

\section{Conlumbia OAnineraity}

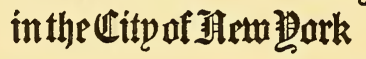

Eollege of 秘ysticians and Surgents

\section{Ifibrary}

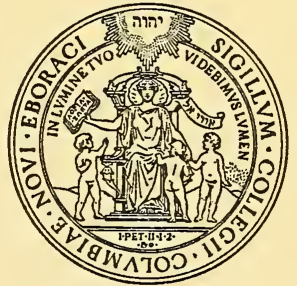







Digitized by the Internet Archive in 2010 with funding from Open Knowledge Commons 


\section{INAUGURAL DISSERTATION \\ o $\pi$}

\section{Worms of the Human Inteftines.}

SUBMITTED TO THE EXAMINATION

O F T H E

Rev. WILLIAM LINN, D.D. F. T. Prefident;

AND TO THE

TRUSTEES AND FACULTY

O F

QUEEN'S COLLEGE, NEW-JERSEY;

FOR THE DEGREE OF

$D O C T O R$ of MEDICINE,

WITH THE RIGHTS AND IMMUNITIES THERELNTO APPERTAINING.

BY HENRY M. VAN SOLINGEN,

OF NEW-YOR K.

MISERIS SUCCURRERE DISCO.

VIRG.

N $E$ WV - Y O R K :

PRINTED ET T. AND J. SWORDS, NO. 27 , WIILIAM-STREET: 


$$
44-16>8
$$

$$
\begin{gathered}
\text { Jae-6o } \\
M-61 \\
R C \\
1197 \\
.136 \\
1792
\end{gathered}
$$




\section{TO THE REVEREND \\ W I L L A M L I N N, D. D。}

Prefident, p. T. of Queen's College, New-Jerfey;

A N D,

Minifter of the Reformed Dutch Church in the City of New - York;

$$
\text { W H O, }
$$

From affiduous Attention to the Duties of his facred Profeflion, and by his eminent Learning and Piety, has contributed to

The Advancement of Religion,

AS WELL AS

The Good and Peace of Mankind:

T H I S

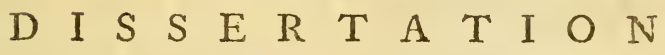

IS I N S C R I BE D,

With every Mark of Refpeet,

By his obliged,

Humble Servant,

The AUTHOR. 


$$
3+2+2+2+2+2
$$

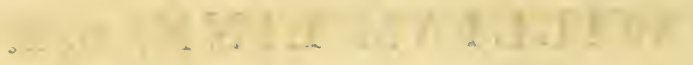

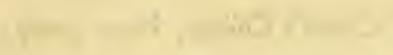

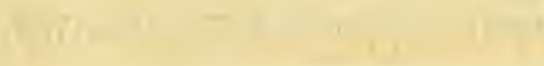

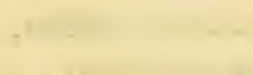

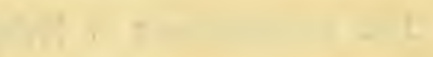

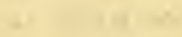

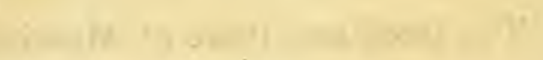

$$
\begin{aligned}
& \text {, }=\text {. }
\end{aligned}
$$

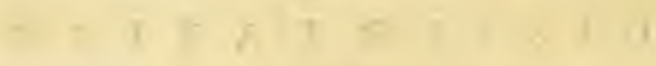

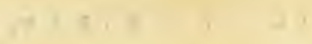

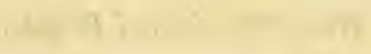

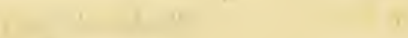

$$
\begin{aligned}
& \text { (1) }
\end{aligned}
$$




\section{INAUGURAL DISSERTATION \\ O N}

\section{Worms of the Human Inteftines.}

\section{I}

INNUMERABLE are the caufes that give rife to difeafes incident to man: fome of them, whilft they appear innocent, and portend little danger, are, at the fame time, both ferious in their nature and termination. For the truth of this, we need only advert to the inftance of buman worms; the confideration of which I propofe to make the fubject of the following difertation.

Every part of the human body has indeed been known to be affected with worms; but it is only thofe inferting the inteftinal canal that are particularly to be confidered here. Their divifion is generally into three kinds-Afcarides, Lumbricus teres, and Tania, or Lumbricus latus. 


\section{Of the $A S C A R I D E S$.}

THE afcarides, Galen has defined, as "being fmall worms, generated chiefly in the lower part of the inteftines." They are of a fmall fize, and pointed at both extremities. The head, in moft, is not eafily detected. Their colour is generailly white, but in fome it has been found changed by the fœces. They abound in great numbers in the colon and rectum, and are frequent- ly thruf out with the excrements. Baglivius* informs us, he knew a young man, who, being fuddenly attacked with diarrhœa, voided an hundred. They excite an intolerable itching, efpecially about the verge of the anus, tenefmus, and other troublefome fymptoms.

THE afcarides have a great refemblance with thofe worms which we frequently fee in cheefe, in point of colour, figure, and fize. Profefior Van Dœverent believed them to derive their origin thence; and Van Sweiten $\downarrow$ knew a man, who, as often as he ate white cheefe, two days after felt a troublefome itching about the anus, occafioned by the afcarides.

* Epift. ad Andry, p. 698.

+ Differtat. Inaug. p. 3!.

$\ddagger$ Com. in Ap. p. 1359. 
But cheefe worms are found to differ widely from afcarides. They undergo a change in their form, which the afcarides do not-They are blunted at the extremities, and the afcarides are fharp.

\section{Of the LUMBRICI TERES.}

THE lumbrici teres, or round and long worms, with which children are ufually troubled, are (by Hippocrates called ì $\lambda$ uvs sgoryvias, by Celfus Teres, ) commonly about fix inches long, and fometimes a foot; but the male is generally fmaller than the female. They are of the thicknefs of a goofequill. Their colour is white, and both extremities terminate in a point.

THE number prefent in the bowels at a time is very various, fometimes only one, two, or three. But if we may judge from the furprifing number of eggs which have been feen in them by means of the microfcope, we will not be aftonifhed at the amazing number of worms prefent in fome perfons, which we find related by fome authors. Clericus mentions the cafe of a boy and girl, who were killed by taking arfenic, having upwards of an hundred of the teres lumbrici in their inteftines. 
Gabucinus faw one hundred and feventy-feven that were voided at one turn by a girl; and, to come nearer home, a woman in this city, a patient of mine, paffed, in four and twenty hours, confiderably more than an hundred, and moft of which were pretty long.

$$
\text { Of the } \mathcal{T} \mathbb{E} N A \text {. }
$$

THE tænia, or lumbricus latus, by fome is called the Solitary Worm, becaufe it has been believed to be always alone. Hippocrates called it Tasia; hence its denomination, Tape-worm.

No fpecies of inteftinal worms is more deftructive to human nature, or more difficult to be totally deftroyed: It fometimes equals in length the whole inteftinal canal; the breadth of it is various, both in the fame worm, and in different worms.

IT confits of a great number of joints, fimply connected together; and thefe joints are fo articulated, that the extreme edges of the preceding come over the fubfequent. The extremity whereon the head is fet, is fmaller than the other, and 
fometimes not an eighth part fo broad: the joints towards the head are confiderably fhorter than towards, the tail, and they feem gradually to grow longer from the head.

THE colour of the tænia is very white, being moftly turgid with chyle.

Four fpecies are enumerated by Linnæus. The firft is diftinguifhed by fmall orifices, or mouths, placed alternately on the margin of each joint, and is called Solium Andrii, Lumbricus latus Couleti et Vermis cucurbitinus Plateri.

THE fecond differs in having two openings on one fide only of a joint, and is called Tania vulgaris Andrii, Tenia primi generis le Clerc.

THE third has only one foramen to be difcovered in the fide of a joint, and this fpecies Linnæus mentions to have been very rarely found.

THE fourth, and laft fpecies, has two little mouths in the margin of each joint, one oppofite to the other.

VAST quantities of this - worm are voided by patients for feveral years together; it is rarely 
ever feen whole. We heve upon record inftances of many yards having been voided at a time.* Olaus Borrichius, a celebrated phyfician of Copenhagen, of the laft century, tells us of a patient of his who paffed eight hundred feet of this fort of worm, in feveral pieces, in the fpace of a jear.

Doctor Tyfon, of London, had a fimilar inftance of great quantities of this worm being voided for feveral years together, in pieces from two to fix yards in length; which all put together would exceed the length of that of Borrichius.

BuT though the exact length of this worm cannot be afcertained, yet it is undeniable that it is prodigiouny long, as appears by thofe pieces mentioned above. The illuftrious Van Dœveren relates the care of a young man, who ejected a broken piece of the trinia that meafured 40 cubits. +

Is the Philofophical Tranfactions we have a defcription of a part of this worm that contained 507 joints; and, to conclude this part, we thall infance one other cafe that the illuftrious Boerhave

* Doctor Buxion, a phyfician of this city, has in his pofferfron, a broken part of a tænia, 24 feet long, and with its hesd complete.

i $A$ cubit is 18 inches. 
have defcribes, which he fays meafured 300 cubits, and confifted of $2 r, 600$ joints.

IT is unknown, as yet, whether each joint feparately conftitutes a whole animal. It is wonderful that each part pofferfes the fame power within itfelf as the whole animal : * it fupports life; moves, and adheres to the other parts. Some injections; tending to afcertain this truth, feem to prove that thofe many joints we fee in each tænia conftitute only one worm.t"

\section{Of the ORIGIN and NOURISHMENT of INTESTINAL WORMS.}

THE various opinions which have been handed down of the origin and nourifoment of worms, are not expected to be prefented in fo fmall a work as this. Some ancient authors believed them to arife from putridity, $f$ and others to have been coeval with the body. Galen, writing upon this fubject, fays, "That thofe worms do not arife from a feed, but from putrid matter." The celebrated phyfician, De Lifle, obferved in his

* A fimilar inftance is in the Polypus.

+ Doctor Monro's Works.

\pm Galen. 
own daughter, a child eleven weeks old, whole netts of worms; and the mother, as yet, had afforded no other kind of nourifhment but that of the breaft. Hence he concludes the worms to be congenial with the body. The eminent phyfician Van Dœveren, collected many obfervations of foetufes that had worms in the intertines whilft yet in the mother's womb. It is however believed to be a univerfal law of nature, "that every animal is generated from an egg." This appears efpecially to be the care, fince eggs have been difcovered in the ovaria of viviparous animals.From the great variety of opinions delivered to us concerning the generation of worms, it will not be wondered at, that the moft learned men in natural hiftory have found fo much difficulty upon the fubject. In Baglivius we read of worms feen in the pericardium equalling in length the whole palm of the hand.

DU VGRNEY tells us of a child, five years old, that conftantly complained of a pain about the root of the nofe; the kept her bed with a flow fever-convulfions at length feized her, and The died: after her death a worm was found in the longitudinal finus of the brain, five thumbs breadth long, and not unlike an earth worm. 
SWAMMERDAM, who was fo fkilful and quicklighted, after carefully confidering all things, confeffes " it is the moft difficult thing in the world to explain by what means worms are generated in living bodies, \&c.-I acknowledge," fays he, "for my part, that I have met with fo few fatisfactory experiments in this matter, that $I$ have not yet any thorough knowledge of the fubject: although I have feen many worms, and worms of various forms, in the living and moving bodies of terreftrial as well as aquatic and ærial animals, but I cannot, in this matter, come to any folid and certain determination:"

WHEN worms are prefent in the inteftines, they, no doubt, muft be nourifhed, as they are fupported and grow; and this nourifhment is afforded by our aliment. Some are of opinion that they live upon the chyle; and others think they live not only on the chyle, but on the blood likewife.Van Dœveren mentions a tænia, which a friend of his faw expelled, where a drop of blood was iffuing from the orifice, or mouth. We have likewife a defcription of a worm* a foot and a half long, and an inch and a half diameter, which was voided by the anus; it was fall of blood, and, for feveral days after its expulfion, the perfon lof, 
to appearance, fome pounds of blood. The worm was dead, and made up of a number of rings like the earth-woim.

Ir appears they draw nourifhment fometimes from the fubftance of the ftomach and bowels, for we very frequently difcover them in the cavity of the abdomen, and a perforation made into the inteftines. Heifter opened the corpfe of a boy, feven years old, who had been troubled for fometime with grievous pains of his abdomen; and although he had an excellent appetite, yet he apparently died of emaciation. In the abdomen was found a quantity of yellow water, which being abforbed, he difcovered many round and long worms; and though the body was opened the day after its death, he found only one living worm among the great number prefent. The fmall inteftines were perforated with many holes, and contained yet many more worms, but every one dead. * We have the hiftory of a young woman's cafe who had fuffered under many difeafes, and died in confequence of worms; her abdomen was found abounding with them. In other cafes not the inteftines alone were perforated, but the heart and liver were eroded. - The late Doctor Bond, + of

Philadelphia,

* Morgag. Let. xxxiv. Art. ${ }_{3}$ 5.

+ Med. Obferv. vol. i. p. 72 . 
Philadelphia, relates a cafe of a Quaker lady who had confiderable part of the liver eroded by a worm.*

\section{Of the CAUSES of WORMS.}

INFANTS labour more frequently and grievoufly under worms than adults; hence arife in them other difeafes: their inteftines being replete with a glutinous matter from the nature of their aliment, which affords a nidus for worms. It is daily to be noticed that children of the poor, far more often than others, labour under this complaint, on account of the want of proper food.

MANY crude indigeftible vegetables, immature fruits, legumina, fweets, cheefe and frefh firh, tend exceedingly to produce the pituitous matter which favours their production, particularly in perfons of debilitated habits.

The feafon of the year favours much the predifpofition to worms. It is mentioned by Van Swieten, $f$ that it was obferved at Beziers, in the

* I am informed the celebrated Doctor Monro thews preparations of inteftines which were actually eroded by worms.

+ Co:n. in aph. 1362. 
year 1730 , to have feized many in the manner of an epidernic. Although worms were frequent at other feafons among the inhabitants, yet, in that year, perfors of both fexes, of all ages and conftitutions, were afflicted with them, and that to fuch a degree as to prove mortal to fome. Remedies were adminittered in vain, if not given very ftrong and powerful, that the worms might be forced out, either upwards or downwards-many of which came alive from the body.

\section{The SYMPTOMS of WORMS.}

IT is not furprifing that worms produce fo many evils, if we only confider the great fenfibility of the inteftines, which exceeds that of almoft. every other part; and the fympathy, which fubfifts between them and every other part of the body: Then, if we confider the ufes they are deftined to in the animal œconomy, with the affections that are attendant on worms, as fordes, gnawing pains, fpafms, flatus, tormina, \&c. it will fufficiently appear that this difeafe is at times exceedingly diftreffing.

THE numerous fymptoms which are attendant on worms in the bowels, affect much more fenfi- 
bly infants than adults, which is plainly enough underftood by perfons who are acquainted with the animal œconomy. Thefe are as follow:The abdomen becomes hard and diftended with air, rumbling noife takes place frequently in it, fetid breath, naufea and vomiting; the appetite is at times impaired, then again it is ravinous and infatiable; heart-burn, hiccup, and tranfient pains of the belly, which are fevere and lancinating when the ftomach is empty: a ceffation or remifion of thefe pains after taking of food, great thirft and palenefs of the countenance. The adnata of the eyes is tinged with a leaden colour-the inferior palpebræ become tumid, are circumfribed with a bluilh ring, and the pupils are dilated; * an itching of the nofe-the upper eye-lid becomes enlarged, as if inflated-frequent ftarting in fleep, and grinding of the teeth-febrile fymptoms occur throughout the day, with pain of the head, and fometimes delirium-an involuntary difcharge of faliva, particularly during fleep.

Dостов. Friend enumerates, among the moft frequent fymptoms of worms, a dry cough, which is exceffively troublefome.

C

The

* Ir may be doubted whether the dilatation of the pupils may be confidered as a fymptom of worms; as the fymptoms of hydrocephalus are very fimilar to thofe of worms, and are often confounded. 
THE belly is mortly bound-The urine is frothy and of a whitifh appearance.

Many other worfe fymptoms arife from their prefence, as eroding and perforating the inteftines, as mentioned already: nor are examples wanting to thew that worms give rife to various convulfive and nervous affections.

THE fymptoms of afcarides, though not very dangerous, yet, if their number become great, and happen to perfons of fenfible, delicate habits, they produce much uneafinefs in the body. They induce an intolerable itching in the inteftinum rectum, and this itching may increafe fo much that, by the confent of the different parts, it may be propagated, and excite fpafmodic affections in the neighbouring parts, as difficulty of voiding urine, itrangury, hemorrhoidal flux, \&rc.

\section{DIAGNOSTIC SIGNS of WORMS.}

THE many dangerous fymptoms induced by the prefence of worms in the body, render it very neceffary that a phyfician fhould underftand the fymptoms indicating the real nature of the difeafe, 
leaft he prefcribe remedies proper for worms, when the complaint requires very different medicines.

IN infants worms are manifeftly more eafily detected than in adults.

$E_{A C H}$ fpecies of worm are faid to have peculiar figns and fymptoms diftinguifhing their prefence: Thus pains, gripings, heart-burn, and troublefome fpafmodic fymptoms, more frequently indicate the teres lumbrici than any other. The tænia, it is faid, is accompanied with a much more depraved appetite, emaciation and fyncope, with an enlarged abdomen, \&c. though this latter often happens when the teres alone are prefent. The proper figns of the afcarides are a vehement itching of the anus, tenefmus, and frequent inclination to ftool. Notwithftanding, all thefe fymptoms may occur, yet no worms may be prefent; but, when worms are difcharged from the bowels, it is prefumable that the fymptoms proceed from that fource.

In the Edinburgh Medical Effays, Profefior St. Clair* relates a cafe of this nature-A boy, four years of age, complained of pains of his ftomach, itching of the nofe, ftartings in fleep, 
and would wake very much terrified; and afterwards, fleeping or waking, he kept continually rubbing his nofe-convulfions fucceeded, and he died the fixth day-having tried many remedies indicated in fuch a cafe. The body was opened, and the ftomach and inteftines diffected throughout their whole length-no worms appeared; but about two ounces of a vifcid fubftance, like gelly, was found fituated at the beginning of the inteftinum jejunum.

The Illuftrious Morgagni* mentions another cafe of the falacy of fymptoms - A boy, feventeen months old, was fuddenly feized with a diarrhœa, attended with cough and itching of the nofe: in a few days he died. Upon infpecting the body, there were no worms found in the inteftines.

Doctor Armftrongt relates a cafe of a boy "who lay very ftupid, pulfe low and quick, tongue foul, and breath fetid; he had no found fleep, but flumbered with his eyes half thut; he grinded his teeth, had inward fits, and was fometimes threatened with convulfions - after a few days he died. The body was opened, and the ftomach and the whole inteftinal canal examined, but not the leaft appearance of worms."

* Eqifr. xxxi. art. 5. de caufiz et fec. morb.

$\rightarrow$ Difeafes of Children. 
The CAUSE of the SYMPTOMS.

ALMOST all the fymptoms of worms may be explained from the wafte of the chyle, a certain matter furnithed by the worms, and from irritation of the inteftines.

BY the rorms confuming the chyle, may be explained the hunger, palenefs, emaciation, debility, and bound belly, with the belching of wind, and rumbling noife of the bowels.

FROM the matter furnined by the worms, we may underftand the caufes of diarrhœa and fetid breath.

By irritating the inteftines, they caufe naufea, vomiting, fyncope, itching of the nofe, and various convulfive affections, as epilepfy, convulfions, \&ce.

\section{The $M E T H O D$ of $C U R E$.}

FROM the nature and fituation of worms, the following indications feem aptly to arife. 
I, To deftroy the neft of worms, diflodge them of their lurking-places, and kill, or induce fuch a ftate of the ftomach and inteftines, as is incompatible with their exiftence.

II. BEING difladged or killed, they are to be expelled from the body.

$T_{H E}$ firlt indication very often fuffices alone, as worms being removed from their fituations, and weakened, are often expelled with the fœces, by the periftaltic motion of the inteftines; but as this is not univerfally the cafe, it becomes neceffary to form another indication for their expulfion.

THE remedies recommended for the firft intention may be divided into fuch as act,

I. BY their poifonous quality;

2. By their mechanical power; and,

3. By the conjoined action of each of thofe.

Those which act by their poifonous quality are cabbage-tree bark, Indian pink, male fern, wormfeed, and common falt.

Cabbage-tree bark.] IT has a mucilaginous fweetifn tafte, and a difagreeable finell; it is given in form of powder, decoction, and extract. It produces 
produces fome ficknefs and purging, fometimes violent effects, as vomiting, delirium, and fever; which are fuppofed to arife from an over dofe, and are faid to be relieved by taken warm water, cafter-oil, or a vegetable acid. In the WeftIndies, where its ufe is better underftood, they ufe it by way of infufion, and begin with fmall dofes, and when cautiouny and properly adminiftered, it affords an excellent anthelmintic, efpecially for the expulfion of the lumbrici.

Indian pink.] THIs plant is made very frequent ufe of in this country, and it proves a pretty certain vermifuge. It is commonly adminiftered in infufion; and its purgative effect, afiifted by fome fuitable medicine.

FROM the experiments of Doctor Francis Home, it appears that it produced the expulfion of worms, when they had evaded other remedies. He fays he found it necefiary to continue the medicine eight or ten days, and, during the ufe of it, he never difcovered any giddinefs, blindnefs, convulfions, or other dangerous fymptoms enumerated by authors, to arife from the ufe of it. - He gave to a boy, eight years old, ten grains twice a day, and to an adult, an half a drachm four times a day. 
Male fern.] THis remedy is the celebrated fpecific of Madam Noufer, of Switzerland, for the cure of the tænia-Having attracted the notice of the practitioners of France, her fecret, after being tried at Paris under the direction of fome eminent phyficians, was purchafed by the French King, and publifhed by his order. The virtues of this plant were well known to the ancients, as early as the days of Diofcorides; but it is faid to have been entirely neglected. Galen mentions the fuccefsful uie of $i t$, and orders it to be drank with mead.

IN the Academy of Sciences of Paris, in the year I70I, Marchand made many experiments upon its ufe, and declares it to be a certain remedy in expelling all kind of worms.

Doctor Duncan, in his Medical Cafes, has exhibited a cafe of tænia, wherein the powder of the male-fern proved fuccefsful. He adds, "If the prefent practice Thall confirm the opinion of the ancients, the reftoration of this article, to the lift of the materia medica, may be confidered as a circumftance of importance in the practice of medicine." He fays alfo, he has every reafon for prefuming that the expulfion of the tænia was, in a great meafure, owing to the influence which the 
fern powder exërted, as a degree of ficknefs at the ftomach arofe before any other medicine was exhibited.

THE root of the male fern, in powder, is directed to be taken in water, to two or three drams in the morning, no fupper having been ate the preceding night-It generally fickens a little-A brifk cathartic is given a few hours after, confifting of calomel, fcammony, and gamboge. This frequently brings off the tænia entire; if not, the medicine is repeated at due intervals.

THE French phyficians recommend fome precautions, which they affirm are effential to the fuccefs of the remedy, as giving fome panada and an injection, which they prefcribe the night before, to lubricate the inteftines, and prepare the prima viæ.

Worm-feed.] This feed has an unpleafant fmell, and a very bitter tafte; and, on account of thefe qualities, the form of powder and decoction is rendered inconvenient-It is celebrated as a vermifuge, and is readily taken mixed with molaffes.

In the Medical Commentaries, vol. viii. page 213, the fuccefsful effects of the anthelmia ber- 
mudenfis, or common worm-grafs, is mentioned. as an anthelmintic, while, at the fame time, it is perfecly inoffenfive. It is fuppofed to be the fame plant from which the femen fantonicum, or wormfeed, is taken: It may be given in infufion; but the author found the following a pretty certain vermifuge $-R$. Antkelm. Occidentalis (common worm-grafs) unciam unam, Canell. Alb. fcrupulos duos, pulv. jalap. forupulum unum, vitriol, corul grana decem M. From ten grains to two fcruples may be given once or twice a day, according to the age of the perfon.

Common falt.] From the experiments related in the Medical Commentaries, vol. viii. page 342 , and thofe of the ingenious Doctor Rufi, of Philadelphia, of the fudden and powerful influence of this falt in killing worms out of the body, I have been led to mention it here. In the experiments alluded to, a watery folution of this falt being applied to earth-worms ftrongly convulfed them in one or two minutes, in three they became motionlefs, and in four minutes they died.

Doctor Rufh fays, he "6 adminiftered many pounds of common falt, coloured with cochineal, in dofes of half a drachm, upon an empty ftomach in the morning, with great fuccels in deftroying worms." 
WE might go on to enumerate many more articles which act by their deleterious quality, but the limits of this differtation will not permit. Thofe of the moft approved efficacy have been felected, and briefly treated.

2. THE mechanical medicines act directly and indirectly upon worms.

Those of the firt kind are cowhage, flings of fteel, and powder of tin.

Cowbage.] THE efficacy of this plaint is now indifputable, and the dangerous confequences apprehended formerly from its contact with the coats of the ftomach and inteftines, are now happily removed.

THE parts of this plant which are made ufe of, are the fpiculæ or hairy fubftance growing on the outfide of the pod. Thefe are given mixed with molafies or common fyrup. The fpiculæ of one pod are faid to be a fufficient quantity for an adult.

A Practitioner* who refided in the WeftIndies, previous to the late war, made feveral experiments to determine whether the innocency of the remedy, when taken into the ftomach, was to be attributed to the mode of its exhibition, or to 
the mucus with which the fromach is lined; judgeing its activity might be blunted by the fyrup of the one, and mucus of the other, which, however, proved not to be the cafe. He applied to the back of one of his hands a fmall portion of the dry fpiculæ, and to the other a like quantity mixed with fyrup, without being able to perceive any difference in their effects, in point of duration or feverity: Hence he concludes the ftimulating properties of cowhage are conveyed into the ftomach with it.

IN the next experiment he blended a fmall quantity of the fpicula with fome faliva, and put it to the back of his hand; at the fame time he took fome dry cowhage into his mouth, and obferved that what he had applied to his hand quickty produced confiderable uneafinefs, while that which was taken into the mouth had no fenfible effect.

Finding its fimulating effects to be fo gentle and inofienfive upon the parts lining the mouth and intertines, and not knowing any other quality to which its properties as an anthelmintic could be attributed, more particularly as he had adminiftered it in tincture and decoction, without any eviaent advantage, he made the following experiment, which removed the objections:- 
To a number of earth-worms, when quiet and undifurbed, he applied fome cowhage, and as foon as it came in contact with them, they manifefted figns of uneafinefs, by their violent agitation; and the fame thing was noticed when applied to them united with molafies or fyrup, and it eventually proved their death.

Filings of fteel.] This preparation is exhibited againft the lumbrici and tænia. Some phyficians have adminiftered it to the quantity of a drachm in a day, which was repeated for feveral fucceffive days.

Powder of tin.] THIs has been fuppoled to act as a poifon to the worms, from the arfenic that is combined with it in its pureft ftate; but from the length of time a worm can live in a folution of white arfenic, it is more likely that the tin acts entireiy by its mechanical property upon the worms.

Proressor Alfon publifhed in the Medical Effays, vol. v. page 9o, an empirical remedy of tin againft worms, from which he experienced great fuccers. The method he prefcribes for ufing it was as follows:-For an adult perfon, to have two ounces of the pureft powder of tin mixed 
with eight ounces of common fyrup or molafies; and previoufly to its exhibition, to have the bowels well emptied by an infufion of fenna and manna, \&xc. The day following, fuppofe Monday, he direets one half of this mixture to be taking early in the morning, upon a fafting ftomach. On Tueflay, at the fame time, he orders a fourth part of it; and, on Wednefday, the remainder, in like manner as the former; and laftly, on Thurfday he again directs the patient to be purged by the above purgative medicine, to evacuate the worms in the body.

THE celebrated Doctor Mead* found the fileings of tin a moft efficacious remedy againft the tania, and made ufe of it for a very long time before he publifhed it. He tock equal portions of filings of tin and red coral, reduced to a very fine powder; a drachm of which he directs to be taken, made into a bolus, with conferye of the tops of wormwood, twice in a day.

THE mechanical medicines which act indirectly upon the worms, are vomits, purges, and thofe remedies that give tone and vigour to the ftoniach and bowels.

3. THE

* R. Mead's Prceepta Med. cap. de Lumbricis. 
3. THE remedies which ac by their mechanical and poifonous qualities conjointly, are calomel and jalap. Thefe are fafe and powerful; they often caufe an evacuation of worms when given with other intentions.

II. THE worms being diflodged or killed, they are to be expelled from the body.

THIs indication may be fulfilled, by exhibiting in conftitutions that are pretty frong, all thofe purgative medicines accounted draftic, as gamboge, fammony, infufion of fenna and falts, \&x. \&c. \&cc. But in children powdered rhubarb alone, or united with mercurius dulcis, is an effectual purgative, and anfwers extremely well.

From the fituation of the afcarides in the inteltines, medicines taken by the mouth very rarely preferve their efficacy until they arrive at the inteftinum rectum, as thefe worms are principally feated in it; hence they are more immediately and effectually killed and expelled by clyfters of an oily, acrid, or fweet nature, and by acrid fuppofitories, with remedies of a like nature; but what many think more fafe and certain remedies, are clyftes of lime-water, injections of fulphurious mineral-waters, and the vapours of tobacco thrown up. 
Clysters adminiftered againit the afcarides ought to be frequently repeated, as fometimes they do not infeft the reoum in great numbers; and in that cafe the few that do, get feated in the folds of the rectum.

In the London Medical Tranfactions we have an account of a boy, who, as often as he perceived fymptoms of afcarides, immediately took air half pound of common falt, difolved in water; in confequence of which he roided them, and afterwards recovered.

After having exhibited fome of the foregoing remedies, and having expelled the worms, it will be advifeable to give, at proper intervals, fome gentle cathartic; and hould the inteftines be much debilitated, fome frengthening medicines ought to be taken, as bark and red wine; at the fame time, ufing exercife: and indeed nothing feems to be more deftructive to worms, or more effectual in preventing their generation, than good living. 




\section{COLUMBIA UNIVERSITY LIBRARIES}

This book is due on the date indicated below, or at the expiration of a definite period after the date of borrowing, as provided by the rules of the Library or by special arrangement with the Librarian in charge.

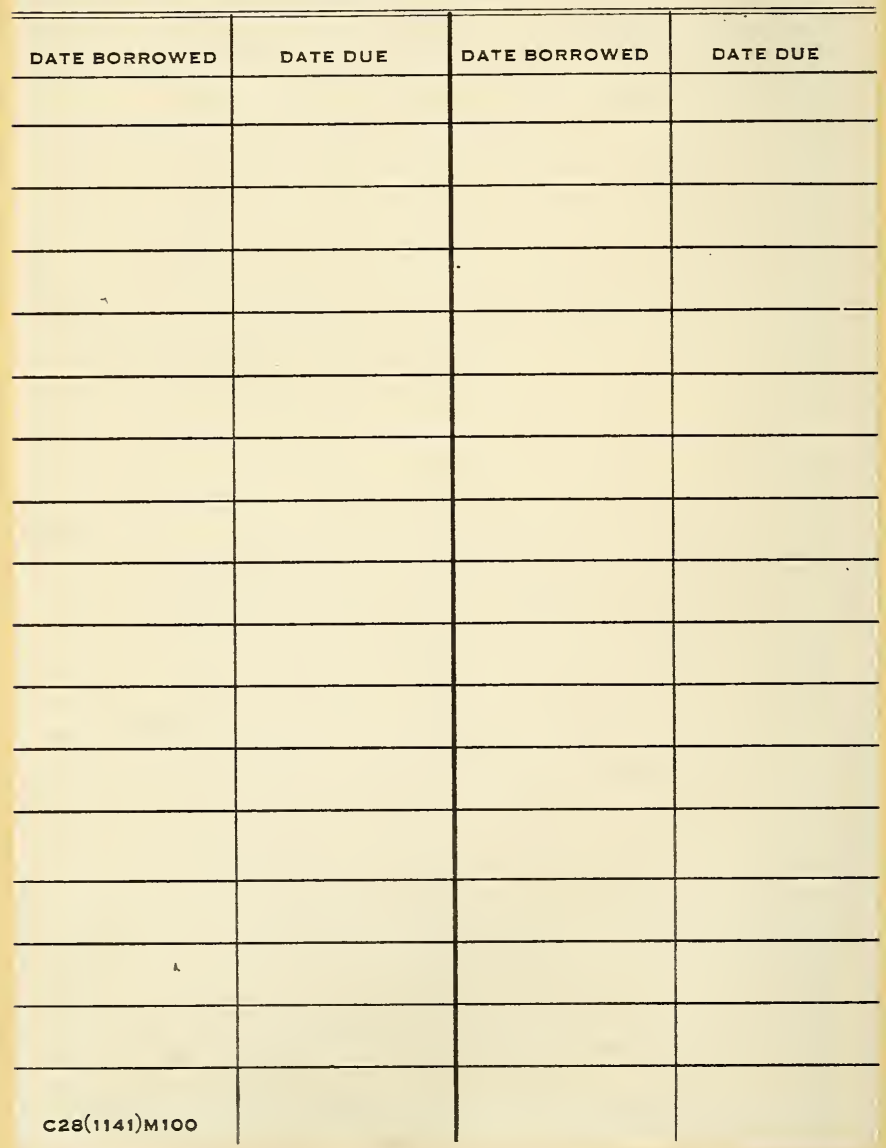




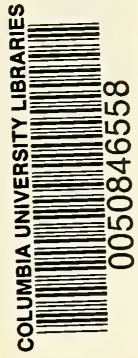

$M-2$ 
